\title{
Hyperglycemia induces apoptosis in rat liver through the increase of hydroxyl radical: new insights into the insulin effect
}

\author{
Daniel E Francés ${ }^{1}$, María T Ronco ${ }^{1}$, Juan A Monti ${ }^{1}$, Paola I Ingaramo ${ }^{1}$, Gerardo B Pisani ${ }^{2}$, Juan P Parody ${ }^{1}$, \\ José M Pellegrino ${ }^{1}$, Paloma Martín Sanz ${ }^{3,4}$, María C Carrillo ${ }^{1}$ and Cristina E Carnovale ${ }^{1}$ \\ ${ }^{1}$ Instituto de Fisiología Experimental (IFISE-CONICET), ${ }^{2}$ Area Morfología, Facultad de Ciencias Bioquímicas y Farmacéuticas (Universidad Nacional de Rosario), \\ Suipacha 570, 2000 Rosario, Argentina \\ ${ }^{3}$ Instituto de Investigaciones Biomédicas 'Alberto Sols', IIBM, Consejo Superior de Investigaciones Científicas, CSIC-UAM, Arturo Duperier 4, 28029 Madrid, \\ Spain \\ ${ }^{4}$ Centro de Investigación Biomédica en Red de Enfermedades Hepáticas y Digestivas (Ciberehd), Villaroel 170, 08036 Barcelona, Spain \\ (Correspondence should be addressed to C E Carnovale; Email: ccarnova@fbioyf.unr.edu.ar)
}

\begin{abstract}
In this study, we analyzed the contribution of hydroxyl radical in the liver apoptosis mediated by hyperglycemia through the Bax-caspase pathway and the effects of insulin protection against the apoptosis induced by hyperglycemia. Male adult Wistar rats were randomized in three groups: control (C) (sodium citrate buffer, i.p.), streptozotocin (STZ)-induced diabetic (SID) (STZ $60 \mathrm{mg} / \mathrm{kg}$ body weight, i.p.), and insulintreated SID (SID + I; 15 days post STZ injection, SID received insulin s.c., twice a day, 15 days). Rats were autopsied on day 30. In liver tissue, diabetes promoted a significant increase in hydroxyl radical production which correlated with lipid peroxidation (LPO) levels. Besides, hyperglycemia significantly increased mitochondrial BAX protein expression, cytosolic cytochrome $c$ levels, and caspase-3 activity leading to an increase in apoptotic index. Interestingly, the treatment of diabetic rats with desferoxamine or tempol (antioxidants/ hydroxyl radical scavengers) significantly attenuated the
\end{abstract}

increase in both hydroxyl radical production and in LPO produced by hyperglycemia, preventing apoptosis by reduction of mitochondrial BAX and cytosolic cytochrome $c$ levels. Insulin treatment showed similar results. The finding that co-administration of antioxidants/hydroxyl radical scavengers together with insulin did not provide any additional benefit compared with those obtained using either inhibitors or insulin alone shows that it is likely that insulin prevents oxidative stress by reducing the effects of hydroxyl radicals. Importantly, insulin significantly increased apoptosis inhibitor protein expression by induction of its mRNA. Taken together, our studies support that, at least in part, the hydroxyl radical acts as a reactive intermediate, which leads to liver apoptosis in a model of STZ-mediated hyperglycemia. A new anti-apoptosis signal for insulin is shown, given by an increase of apoptosis inhibitor protein.

Journal of Endocrinology (2010) 205, 187-200

\section{Introduction}

Diabetes is a common metabolic disorder in humans, which is associated with significant morbidity and mortality, and is a contributor to the development of other diseases. Indirectly or directly, the liver is a major target of insulin action. The onset of diabetes is accompanied by development of major biochemical and functional abnormalities in the liver, including alterations in carbohydrate, lipid, and protein metabolism, and changes in antioxidant status (McLennan et al. 1991, Saxena et al. 1993, Chatila \& West 1996, Harrison et al. 2006). The prevalence of hepatobiliary diseases is increased in patients with either type 1 or type 2 diabetes (Saxena et al. 1993, Bell \& Allbright 2007). Even with insulin treatment, diabetic patients show profound disturbances in tissue growth (Porte \& Schwartz 1996). Clinically, altered liver size is seen in both juvenile and adult diabetic patients, which can be the result of alteration in cell number, cell growth, and/or cell death (apoptosis; Chatila \& West 1996, Marangiello \& Giorgetti 1996).

West indicated an increase in oxidative damage in both type 1 and type 2 diabetes as well as deficits in antioxidant defence enzymes and vitamins. It is argued that oxygen, antioxidant defences, and cellular redox status should be regarded as central players in diabetes (West 2000). Laaksonen et al. reported increased lipid peroxidation (LPO) in plasma of young men with type 1 diabetes using the malondialdehyde (MDA) test. MDA is formed when polyunsaturated fatty acyl chains are attacked by hydroxyl radicals, which can also damage DNA-generating characteristic products, i.e. 8-hydroxy-2 deoxyguanosine (Laaksonen et al. 1996). There is accumulating evidence especially in diabetic animal models 
(such as streptozotocin (STZ)-induced diabetic (SID) rats and mice) that hyperglycemia induces acceleration of hydroxyl radical generation and this has been correlated with the level of thiobarbituric acid (TBA) - reactive compounds as an estimation of LPO (Ohkuwa et al. 1995, Winiarska et al. 2004).

On the other hand, it was established that hyperglycemia increases mitochondrial reactive oxygen species (ROS) production, which could represent a key event in the development of diabetes complications (Nishikawa et al. 2000, Kiritoshi et al. 2003). The initial cellular response to high glucose challenge is the generation of ROS, which rapidly induces apoptotic cell death (Park et al. 2001).

It is known that high D-glucose induces endothelial apoptosis through activation of the Bax-caspase proteases pathway. The effectors of apoptosis are now well known to be represented by a family of intracellular cysteine proteases known as caspases (Green \& Reed 1998). A feature of apoptosis that impinges on caspases is altered mitochondrial function characterized by a reduction in the electrochemical gradient across the mitochondrial membrane and release of mitochondrial cytochrome $c$ to cytoplasm (Liu et al. 1996), and it is inhibited by the presence of $\mathrm{Bcl}-\mathrm{xL}$ in these organelles (Fraser \& Evan 1996, Yang et al. 1997). Translocation of pro-apoptotic BAX protein into the mitochondrial membrane is accompanied by a significant increase in caspase-3 (CASP3) and caspase-9 (CASP9) activities (Nakagami et al. 2002).

Several studies have been carried out to evaluate the alterations in cell mitochondrial functions from brain, heart, liver, and kidney of diabetic rats (Moreira et al. 2006). However, results are sometimes controversial, since experimental conditions such as age and strain of used animals are diverse.

In view of the above lines of evidence, the objective of the present study was to investigate whether hyperglycemia produces an increase in hydroxyl radical, which exerts a regulatory action on apoptosis in liver through the Bax-caspase pathway. In addition, the effect of insulin over this pathway was also evaluated.

\section{Materials and Methods}

\section{Animals and treatments}

Experiments were performed in 100-day-old male Wistar rats. They were housed two per cage and maintained in a room at constant temperature with a $12 \mathrm{~h}$ light: $12 \mathrm{~h}$ darkness cycle. Animals were fed with standard pellet diet and water made available ad libitum. All the experimental protocols were performed according to the Regulation for the Care and Use of Laboratory Animals (Expedient 6109/012 E.C. Resolution 267/02) and approved by the Institutional Animal Use Committee of the National University of Rosario, Argentina.
SID was induced by a single dose of STZ $(60 \mathrm{mg} / \mathrm{kg}$ body weight (bw), i.p., in $50 \mathrm{mM}$ citrate buffer, $\mathrm{pH} \mathrm{4.5}$; Ha et al. 1994). Rats of the control group (C) $(n=6)$ received an i.p. injection of an equal volume of citrate buffer. It is known that STZ is excreted within $48 \mathrm{~h}$ from injection and therefore cannot be a direct effect of oxidative stress (Karunanayake et al. 1974). Fifteen days after STZ injection, a time when the toxic effect of the drug on the liver would have disappeared (Carnovale \& Rodriguez Garay 1984, Carnovale et al. 1986), blood samples were obtained from the tail vein, and glucose concentrations were measured by means of a Surestep glucometer (Glucostix, Bayer HealthCare). Successful induction of diabetes was defined as a blood glucose level of $>13 \cdot 2 \mathrm{mmol} / \mathrm{l}$. On day 15 post STZ treatment, SID rats were randomly assigned to two groups ( $n=6$ each group): diabetic animals (SID) and insulin-treated diabetic animals (SID + I). Insulin (Betasint insulin, BETA S.A. Laboratories, Buenos Aires, Argentina) was administered s.c. twice a day (at 0800 and $2000 \mathrm{~h}$ ) until the animals were killed. Blood glucose levels were measured every day, each time just before insulin injection. The doses of insulin were adjusted to reach target blood glucose levels of 6-9 mmol/l. Between 1000 and $1200 \mathrm{~h}$ on day 30, rats were weighed, anesthetized with sodium pentobarbital solution (50 mg/kg bw, i.p.), and killed. Blood was obtained by cardiac puncture. Plasma was separated by centrifugation $\left(2200 \mathrm{~g}\right.$ for $5 \mathrm{~min}$ at $4{ }^{\circ} \mathrm{C}$ ). Liver was promptly removed, and slices of liver tissue were processed for immunohistochemical studies. Remaining liver tissue was stored at $-70{ }^{\circ} \mathrm{C}$ until the analytical assays were performed.

For hydroxyl radical detection, other four rats belonging to each different group under study (C, SID, SID + I, SID + desferoxamine (DES), SID + DES + I, SID + tempol (TEM), and SID + TEM + I) were injected with trapping agent salicylic acid (SA; $100 \mathrm{mg} / \mathrm{kg}$ bw, i.p.) $30 \mathrm{~min}$ before the animals were killed, and the livers were removed.

For studies on inhibition of hydroxyl radical production, after 15 days of diabetes, STZ-induced diabetes rats were separated into different groups and received different hydroxyl radical inhibitors alone or co-administered with insulin. Each group contained at least six animals. DES is an iron chelator that prevents the formation of hydroxyl radicals from hydrogen peroxide via inhibition of the Fenton and Haber-Weiss reactions (Kaur \& Halliwell 1994). DES (100 mg/kg bw, i.p.) was administered to rats, once a day, in saline solution starting 15 days after injection of STZ and for 15 days. TEM is a stable piperidine nitroxide that permeates biological membranes, and reduces the formation or the effects of hydroxyl radicals by scavenging superoxide anions or by reducing intracellular $\mathrm{Fe}^{+2}$ concentrations or by directly scavenging hydroxyl radicals (Chatterjee et al. 2000). TEM $(20 \mathrm{mg} / \mathrm{kg}$ bw, i.v.) was administered to rats, once a day, in saline solution starting 15 days after injection of STZ and for 15 days. 


\section{Hydroxyl radical ('OH) detection}

The in vivo measurement of ${ }^{\circ} \mathrm{OH}$, a highly reactive free radical, is very difficult (Kaur \& Halliwell 1994). Thus, salicylate has been used as a trapping agent for detecting ${ }^{\circ} \mathrm{OH}$ in vivo (Grootveld \& Halliwell 1986, Pryor \& Godber 1991). Attack by ${ }^{\circ} \mathrm{OH}$ upon salicylate produces 2,3-dihydroxybenzoic acid (2,3-DHBA), 2,5-DHBA, and catechol. Among these hydroxylated products of salicylate, 2,3-DHBA is reported to be solely formed by direct ${ }^{\circ} \mathrm{OH}$ attack. As a result, the method of salicylate hydroxylation is useful in predicting the occurrence of oxidative stress in vivo, and the measurement of 2,3-DHBA has been proposed as a marker for the assessment of oxidative stress (Pryor \& Godber 1991). For this experiment, $30 \mathrm{~min}$ after $\mathrm{SA}$ injection $(100 \mathrm{mg} / \mathrm{kg}$ bw, i.p.), the rats were anesthetized with sodium pentobarbital (50 $\mathrm{mg} / \mathrm{kg}$ bw) and killed.

SA and 2,3-DHBA were measured according to the methods of Tsai et al. (1998) and Yamamoto et al. (2001) respectively, both with modifications. For the determination of SA and 2,3-DHBA, tissue samples (within $0.5 \mathrm{~g}$ ) were homogenized in ice-cold saline $(0.5 \mathrm{ml})$, and deproteinized by the addition of $10 \% \mathrm{v} / \mathrm{v}$ perchloric acid containing $1 \mathrm{mM}$ EDTA and $100 \mu \mathrm{M}$ sodium pyrosulfite. Hydrochloride (1 M, $0.4 \mathrm{ml}$ ) was added to the supernatant fraction obtained by centrifugation. The resulting solution was extracted with $10 \mathrm{ml}$ of diethyl ether by mixing thoroughly for $1 \mathrm{~min}$ and was then centrifuged. The organic phase was collected, evaporated to dryness under nitrogen, and dissolved in $300 \mu 1$ mobile phase ( $30 \mathrm{mM}$ sodium citrate $/ 27 \cdot 7 \mathrm{mM}$ sodium acetate, $\mathrm{pH} 2 \cdot 80$ ). According to the method, the samples were analyzed using a Waters HPLC system, equipped with a Model 1515 pump, and Waters 2465 electrochemical detector (ECD; Waters, Milford, MA, USA). Reverse-phase HPLC analysis was carried out using a Luna $5 \mu$ C18(2) 100A column $(250 \times 4.6 \mathrm{~mm}$, Phenomenex, Torrance, CA, USA). The glassy carbonworking electrode was set at a potential of $+0.85 \mathrm{~V}$, and the flow rate was $0.6 \mathrm{ml} / \mathrm{min}$. No interfering peaks were detected in blank samples. To determine SA levels, an u.v. detector was coupled to the system monitoring absorbance at $295 \mathrm{~nm}$. The ratio of 2,3-DHBA to SA was obtained.

\section{Assays for lipid peroxidation}

LPO levels were determined as indirect measurements of ROS production. The amount of aldehydic products generated by LPO in total homogenate fractions was quantified by the TBA reaction according to the method of Ohkawa et al. (1979) and measured by HPLC with modifications introduced by Young \& Trimble (1991). The amount of TBA reactants (TBARS) was expressed in terms of MDA using 1,1,3,3-tetramethoxypropane as a standard. Protein content was measured by the method of Lowry et al. (1951) using BSA as a standard. Results were expressed as nmol of MDA per mg of protein.

\section{Analysis of protein levels by western blotting}

Western blotting was performed for the analysis of AKT, phosphorylated AKT (P-AKT), phosphoinositol-3 kinase (PI3K), BAD, BAX, Bcl-xL (BCL2L1), X-linked inhibitor of apoptosis protein (XIAP), and cytochrome $c$ proteins. Briefly, mitochondria-enriched fractions were prepared from liver tissues that were homogenized in four volumes of $0.150 \mathrm{M}$ $\mathrm{KCl}$ with protease inhibitors $(1 \mathrm{mM}$ phenylmethylsulfonyl fluoride, $10 \mu \mathrm{g} / \mathrm{ml}$ leupeptin, and $1 \mu \mathrm{g} / \mathrm{ml}$ aprotinin). Homogenates were centrifuged at $1000 \mathrm{~g}$ to remove unbroken cells, nuclei, and heavy membranes. Mitochondriaenriched fractions were then obtained by the centrifugation of supernatant at $6000 \mathrm{~g}$ at $4{ }^{\circ} \mathrm{C}$ for $15 \mathrm{~min}$. Then, the supernatant was centrifuged at $45000 \mathrm{~g}$ for $1 \mathrm{~h}$ to obtain the cytosolic fraction (Ronco et al. 2004). Proteins were quantified according to Lowry et al. (1951). For detection, $25 \mu \mathrm{g}$ protein was subjected to $12 \%$ SDS-PAGE and transferred to polyvinyl difluoride (PVDF) membranes (PerkinElmer Life Sciences, Boston, MA, USA). After blocking, blots were incubated overnight at $4{ }^{\circ} \mathrm{C}$ with monoclonal primary antibodies (AKT and P-AKT (1:600, Cell Signaling, Danvers, MA, USA); PI3K p85 $\alpha$, BAD, BAX, BCl-XL, XIAP, and cytochrome $c(1: 600$, Santa Cruz Biotechnology, Santa Cruz, CA, USA)). After this, membranes were incubated with secondary antibodies such as IgG-peroxidase conjugates (1:5000, Amersham Life Science), and the resulting bands were detected by enhanced chemiluminescence (ECL; Amersham Pharmacia Biotech) detection. Autoradiographs were obtained by exposing PVDF membranes to Kodak XAR film, and the bands were quantified by densitometry (Shimadzu CS-9000).

\section{Determination of apoptosis}

Caspase-3 activity and terminal deoxynucleotidyl transferasemediated deoxyuridine triphosphate nick end labeling (TUNEL) assays were performed as quantitative indexes of apoptosis.

\section{Caspase-3 activity assay}

The activity of caspase- 3 was determined according to the manufacturer's instructions using an EnzChek caspase-3 assay kit (Molecular Probes, Eugene, OR, USA). The tissues were homogenized in lysis buffer $(10 \mathrm{mM}$ Tris, $200 \mathrm{mM} \mathrm{NaCl}$, $1 \mathrm{mM}$ EDTA, and $0 \cdot 001 \%$ Triton X-100). Subsequently, after differential centrifugation, the cytosolic fraction from each sample was mixed with Z-Asp-Glu-Val-Asp-AMC substrate solution. A standard curve of AMC ranging from 0 to $100 \mu \mathrm{M}$ was run with each set of samples. A control sample without enzyme was used in each assay to determine the background fluorescence of the substrate. As an additional control, $1 \mu \mathrm{l}$ of the $1 \mathrm{mM} \mathrm{Ac-Asp-Glu-Val-Asp-CHO}$ (aldehyde), the caspase-3 inhibitor stock solution, was added. Fluorescence was 
measured at an excitation wavelength of $360 \mathrm{~nm}$ and an emission wavelength of $465 \mathrm{~nm}$ in a DTX 880 Multimode Detector (Beckman Coulter, Brea, CA, USA).

\section{Determination of apoptotic index}

An apoptosis detection system was utilized which catalytically incorporates fluorescein-12-dUTP at the $3^{\prime}-\mathrm{OH}$ DNA ends using the principle of the TUNEL assay, with direct visualization of the labeled DNA (Promega). Light microscopic analysis of hematoxylin- and eosin-stained slides was used to quantify apoptotic cells, which were identified by morphological criteria (increased eosinophilic cytoplasm, darkened nucleus, and pycnotic separation of cytoplasmic membrane from neighboring cells). To corroborate the incidence of apoptotic bodies, serial sections were stained with hematoxylin-eosin. An apoptotic index (AI) was calculated for each sample by counting the number of positively stained hepatocyte nuclei divided by the total number of hepatocytes and expressed as percentage. The number of apoptotic hepatocytes was assessed by systematically scoring at least 10000 hepatocytes per slide at a magnification of $400 \times$ (Gold et al. 1994, Klainguti et al. 2000).

\section{Measurement of Xiap $m R N A$ levels or $R N A$ isolation and reverse transcription- $P C R$}

Total RNA was isolated using the TRIzol method (Life Technologies). RNA was dissolved in RNAse-free water and kept at $-80{ }^{\circ} \mathrm{C}$ until use. Reverse transcription (RT) of $3 \mu \mathrm{g}$ total RNA was performed with oligo(dT) primer, and cDNA samples were stored at $-20{ }^{\circ} \mathrm{C}$ until assayed. The primers used were Xiap (Bio-Synthesis, Lewisville, TX, USA; sense 5'-TCTGGTGTGAGTTCAGATAGG-3'; antisense $5^{\prime}$-TGGATACCACTTAGCATGCTG- $3^{\prime}$ ) and $\beta$-actin (Genset Oligos; sense $5^{\prime}$-GGTGACGAGGCCCAGAGCAAG-3' $3^{\prime}$ antisense $5^{\prime}$-GATCCACATCTGCTGGAAGGT- $3^{\prime}$ ). The PCR was performed in a GenAmp PCR System 2400 thermocycler (Perkin Elmer) using the following conditions: $94{ }^{\circ} \mathrm{C}$ for $1 \mathrm{~min}, 55^{\circ} \mathrm{C}$ for $1 \mathrm{~min}, 72^{\circ} \mathrm{C}$ for $1 \mathrm{~min}$, and a final extension phase of $72{ }^{\circ} \mathrm{C}$ for $10 \mathrm{~min}$. The number of thermal cycles used was 36 . RT-PCR products were then resolved on a $1.5 \%$ agarose gel, and bands were visualized using a High Performance Ultraviolet Transilluminator (UVP, Upland, CA, USA). Images of the RT-PCR ethidium bromide-stained agarose gels were acquired, and quantification of the optical density
(OD) of bands was performed using the Gel-Pro Analyzer (Media Cybernetics, Bethesda, MD, USA) software (Ronco et al. 2009). Results were expressed as the ratio between the intensities of Xiap and $\beta$-actin, OD.

\section{Statistical analysis}

Data are presented as mean \pm S.E.M. for at least six rats per group. Student's $t$-tests were applied wherever necessary, and statistical analysis of differences between groups was performed by one-way ANOVA followed by Tukey's method. Differences were considered as statistically significant when $P<0 \cdot 05$.

\section{Results}

Assessment of the induced diabetic state: effect of insulin treatment

Diabetes was confirmed in STZ-injected rats by monitoring weight loss and significant increase in blood glucose levels. Compared with control animals, plasma ALT and AST levels were increased by factors of 3 and 2 respectively in the diabetic animals (data not shown). These results are consistent with the STZ model described by others (Barneo et al. 1990, Hwang et al. 2005, Fernandes et al. 2009).

Table 1 shows bw and blood glucose levels in control rats, diabetic rats (SID), diabetic rats treated with insulin (SID + I), and these same three groups treated with DES or TEM. Prior to STZ injection, the bw of diabetic and control rats was similar, and difference was not statistically significant. Thirteen days after STZ administration, the bw of diabetic rats was significantly lower than that of the control group. At this time, the blood glucose levels were significantly increased in SID rats, as compared to control animals. Insulin treatment increased bw and decreased blood glucose levels, reaching the control group values. Treatment with the antioxidants/ hydroxyl radical scavengers DES or TEM produced no changes in these parameters.

\section{Assessment of insulin action}

In order to assess whether insulin was exerting an antiapoptotic effect in our experimental model, we evaluated the classical pathway of hormone action PI3K/AKT (Shepherd et al. 1998, Virkamaki et al. 1999).

We determined the levels of the regulatory subunit of PI3K p $85 \alpha$ and also the levels of P-AKT. AKT has been

Table 1 Assessment of the induced diabetic state. Effect of insulin-treatment. Values are means \pm s.E.M. ( $n=6$ animals per group)

\begin{tabular}{|c|c|c|c|c|c|c|c|}
\hline & Control & SID & SID +I & SID + DES & SID + DES +I & SID + TEM & SID + TEM + I \\
\hline & & $23 \cdot 9$ & $8 \cdot 7 \pm 1$ & $21 \cdot 1$ & $7 \cdot 9 \pm$ & & $8 \cdot 1$ \\
\hline $0,0^{\prime}$ & $447 \cdot 3 \pm 16 \cdot 2$ & $229 \cdot 0 \pm 31 \cdot 5^{*}$ & $397 \cdot 7 \pm 21 \cdot 6^{*, t}$ & $266 \cdot 2 \pm 21 \cdot 3^{*}$ & $366 \cdot 5 \pm 22 \cdot 1^{*, t}$ & $250 \cdot 4 \pm 16 \cdot 3^{*}$ & $347 \cdot 4 \pm 24 \cdot 7^{*,+}$ \\
\hline
\end{tabular}

Control, vehicle; SID, streptozotocin-induced diabetes; SID+I, streptozotocin-induced diabetes treated with insulin; DES, desferoxamine; TEM, tempol. $* P<0 \cdot 05$ versus control; ${ }^{+} P<0 \cdot 05$ versus SID. 
implicated in the suppression of apoptosis through inactivation of several components of the cell death machinery such as BAD (Datta et al. 1997, Galetic et al. 1999).

As expected (Nawano et al. 1999, Katso et al. 2001), the diabetic state reduced significantly both PI3K p85 $\alpha$ and P-AKT expression, as compared to controls. The treatment with insulin restored the levels of both proteins to normal values, thus evidencing the ability of the hormone to regulate the $\mathrm{PI} 3 \mathrm{~K} / \mathrm{AKT}$ pathway in the liver (Fig. 1A-C).
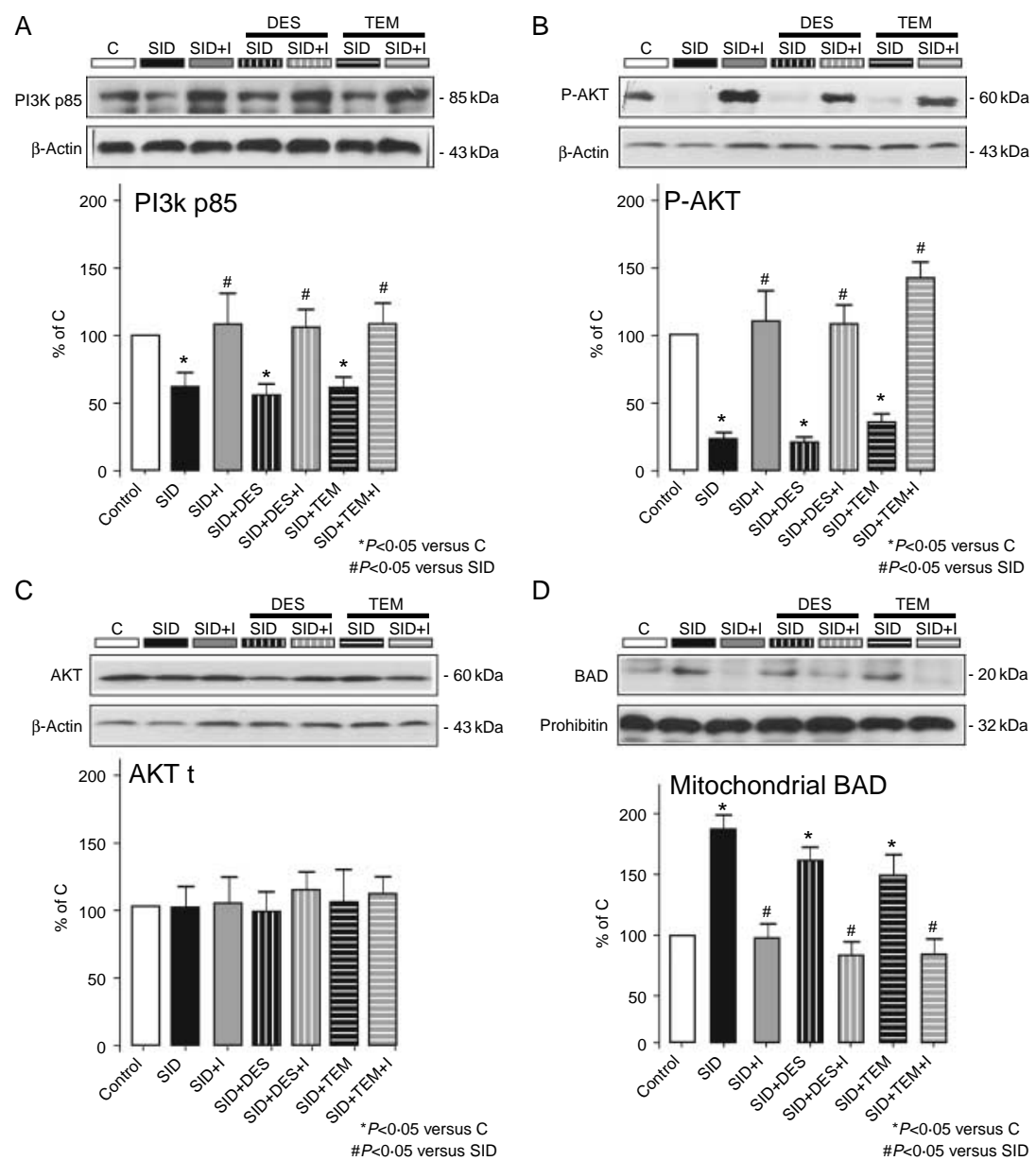

Figure 1 Assessment of the insulin action. Effect of insulin on (A) regulatory subunit p85 $\alpha$ of phosphoinositol-3 kinase activity (PI3K p85 $\alpha$ ), (B) total AKT (AKTt), (C) phosphorylated AKT (P-AKT), and (D) mitochondrial BAD protein expression. The results obtained for all experimental groups are shown as follows: control (C) (white bar), control group of animals injected with sodium citrate vehicle; SID (black bar), streptozotocin (STZ)-induced diabetic rats received an i.p. injection of STZ (60 mg/kg body weight); SID + I (gray bar), on day 15 post STZ treatment, insulin was administered s.c. to SID rats twice a day (at 0800 and $2000 \mathrm{~h}$ ) for 15 days; SID + DES (black vertically stripped bar), desferoxamine $(100 \mathrm{mg} / \mathrm{kg}$ body weight, i.p.) was administered to rats, once a day, in saline solution starting 15 days after injection of STZ and for 15 days; SID + DES + I (co-administration) (gray vertically stripped bar); SID + TEM (black horizontally stripped bar), tempol $(20 \mathrm{mg} / \mathrm{kg}$ body weight, i.v.) was administered to rats, once a day, in saline solution starting 15 days after injection of STZ and for 15 days; SID + TEM+I (co-administration) (gray horizontally stripped bar). Typical examples of western blot of PI3K p85 (A), phospho-AKT (B), total AKT (C), mitochondrial $\mathrm{BAD}(\mathrm{D})$, and $\beta$-actin or prohibitin for all the proteins are shown in top panel. $\ln (A),(B),(C)$, and (D) bottom panels, each bar represents the densitometry expressed in percentage considering control as $100 \%$. Values are the mean \pm s.E.M. of six separated animal sets. Total AKT did not show any change in all the studied groups. PI3K p85 and phospho-AKT showed significant diminution in SID, SID + DES, and SID + TEM when compared to control. Insulin treatment restored $\mathrm{PI} 3 \mathrm{~K}$ p85 levels and increased phospho-AKT in all groups, thus leading to decreased mitochondrial Bad protein expression $\left({ }^{*} P<0 \cdot 05\right.$ versus $C ;{ }^{\sharp} P<0.05$ versus SID). 
Next, we examined BAD levels in mitochondrial fraction. SID rats showed a significant increase of mitochondrial BAD expression. Insulin reduced the levels of this protein, as expected due to its known anti-apoptotic effect (Fig. 1D).

\section{Hydroxyl radical and lipid peroxidation}

2,3-DHBA:SA ratio was determined to evaluate ${ }^{\circ} \mathrm{OH}$ production. Results are presented in Fig. 2A and B. The diabetic state increased ${ }^{\circ} \mathrm{OH}$ production (56\%) compared with the control group $(P<0 \cdot 05)$, and insulin treatment significantly attenuated this increase observed in SID rats $(P<0 \cdot 05)$, thus evidencing its antioxidant capacity. A dramatic decrease in the production of ${ }^{\circ} \mathrm{OH}$ was found in SID rats when DES or TEM was administered. Co-administration of insulin and DES or TEM to SID rats did not have any additive effect on the reduction of liver ${ }^{\circ} \mathrm{OH}$ production compared with that obtained after TEM, DES, or insulin administration respectively (Fig. 2A and B).

It has also been described that the ${ }^{\circ} \mathrm{OH}$ is one of the possible candidates for triggering LPO. We have monitored MDA levels, an LPO product, and a marker of oxidative damage by TBARS assay. MDA is a reflection of the extent of oxidant status and is considered a good marker of oxidative stress (Wen et al. 2006).

MDA levels in liver homogenate of SID animals were significantly higher than those of the control group $(P<0 \cdot 05$; Fig. 2C). Insulin treatment normalized MDA levels in liver homogenate of the SID group $(P<0 \cdot 05)$, suggesting that it is associated with the diabetic state induced by STZ rather than a direct hepatotoxic effect of the drug. This reduction in MDA was not, however, significantly different from the reduction obtained upon administration of DES or TEM alone (Fig. 2C). No changes were observed in these parameters when rats from the control group were treated with the antioxidants/hydroxyl radical scavengers (data not shown).

Figure 2C shows that treatment with TEM produced a larger reduction of LPO in SID than DES. It is known that TEM reduces the formation of ${ }^{\circ} \mathrm{OH}$ either by scavenging superoxide anions or by reducing the intracellular concentrations of $\mathrm{Fe}^{2+}$, and so we hypothesize that other free radical intermediates, in addition to the ${ }^{\circ} \mathrm{OH}$, are contributing to the production of LPO observed in SID rats.

\section{Analysis of the BCL-XL, BAX, and cytochrome c proteins}

We examined the expression of BAX protein in liver mitochondrial and cytosolic fractions, and BCL-XL protein in liver mitochondrial fraction, by western blot analysis in all experimental groups. BAX and BCL-XL are members of the BCL-2 family, which plays a major role as regulators of the apoptotic process: while BAX promotes apoptosis, and BCL-XL protects cells from programed cell death (Tzung et al. 1997). Immunoblot analyses followed by quantitative densitometry from six separate animal sets revealed that mitochondrial BAX protein levels increased by $60 \%(P<0 \cdot 05)$, and a consequent diminution of cytosolic BAX levels was observed when compared to the control group (Fig. 3A).

Treatment of SID rats with insulin (SID + I) markedly decreased the mitochondrial protein levels of BAX reaching the control values; however, protein expression of BCL-XL remained increased when compared to the control group $(P<0 \cdot 05)$. BAX:BCL-XL ratio determines cell survival or death after apoptotic stimuli. Figure $3 \mathrm{~B}$ shows that mitochondrial BAX:BCL-XL ratio was significantly increased in SID rats, indicating that in the diabetic state, the liver is promoted to an apoptotic state. The ability of insulin to decrease the BAX:BCL-XL ratio produces a shift in cell fate towards survival, although the relationship does not reach the control values.

Co-administration of insulin and DES or TEM to SID rats did not have any additive effect on reduction of liver expression of mitochondrial BAX and BCL-XL proteins when compared to that obtained after TEM, DES, or insulin administration respectively (Fig. 3A and B).

Immunoblot analysis of cytosolic cytochrome $c$ showed that there was an increase in its release in SID rats when compared to the control group $(P<0 \cdot 05)$, and a consequent diminution of mitochondrial cytochrome $c$ levels was observed when compared to the control group. Cytosolic cytochrome $c$ protein levels analyzed by quantitative densitometry was increased by $120 \%(P<0 \cdot 05)$ in SID rats compared with the control group. The levels of cytosolic cytochrome $c$ were decreased by treatment with insulin compared with the SID group, thus observing the consequent increase in mitochondrial cytochrome $c$. The changes produced by treatment with insulin did not reach the values of the control group, remaining significantly increased as compared to the control group $(P<0 \cdot 05$; Fig. 3C). Administration of DES or TEM also produced a significant attenuation of cytochrome $c$ in cytoplasm when compared with SID, and a consequent augmentation of mitochondrial cytochrome $c$ levels was observed when compared with the SID group. The changes produced by treatment with antioxidants/hydroxyl radical scavengers did not reach the values of the control group, remaining significantly increased as compared to the control group $(P<0 \cdot 05$; Fig. $3 \mathrm{C})$. Co-administration of insulin and DES or TEM to SID rats did not have any additive effects on the reduction of cytosolic cytochrome $c$ compared with that obtained after TEM, DES, or insulin administration respectively.

\section{Assessment of apoptotic cell death}

Caspase-3 activity and TUNEL assays were performed in order to characterize the effect of diabetic state and insulin treatment on induced apoptosis in the liver. Results are presented in Fig. 4. Caspase-3 activity was assayed in liver cytosolic fraction in all experimental groups and is presented in Fig. 4A. There was a significant increase in the caspase-3 activity in SID rats when compared to the control group 


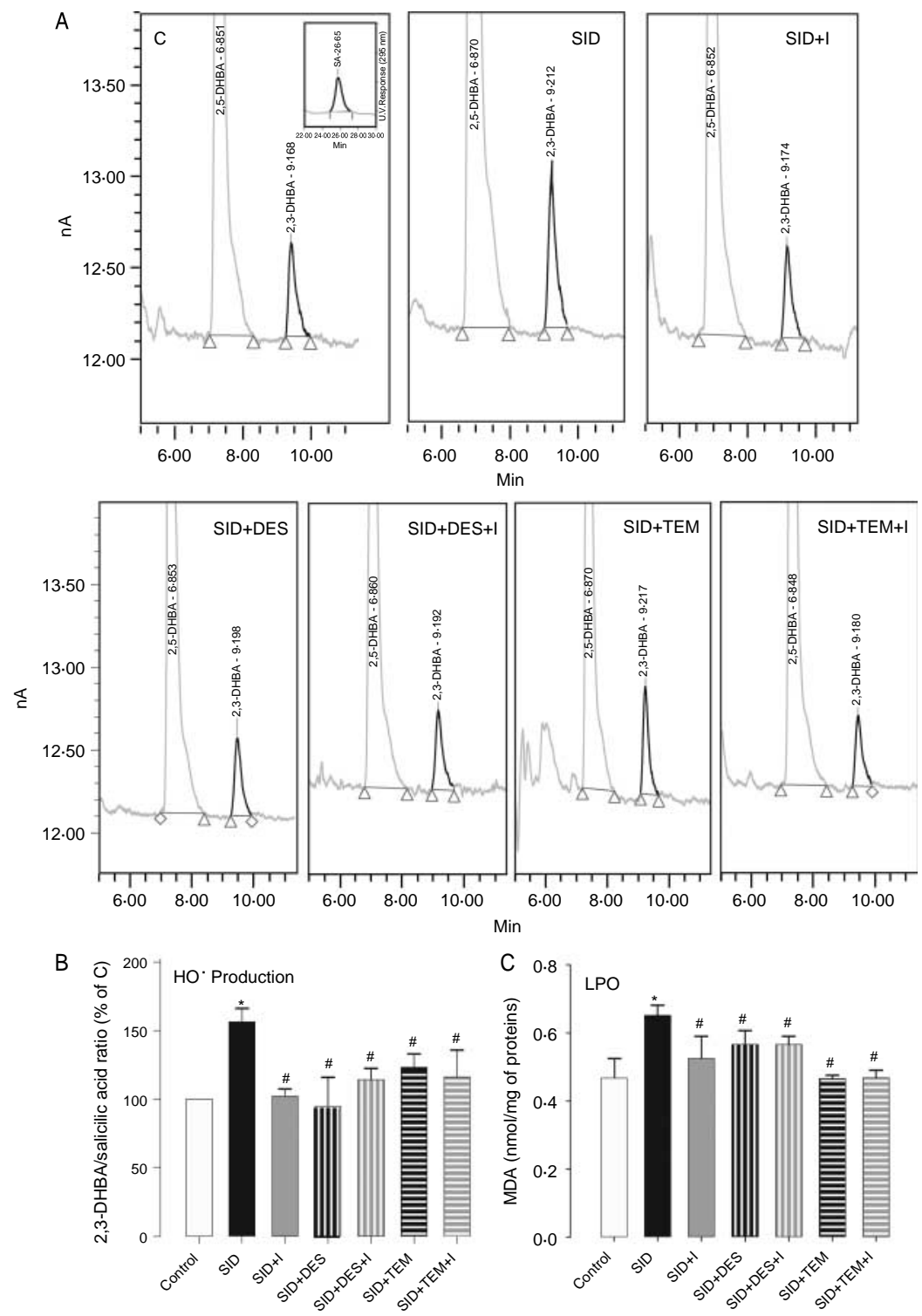

Figure 2 Effect of diabetic state and insulin treatment on hydroxyl radical production. (A) Representative chromatograms of samples obtained for each experimental group are depicted. Inset: a representative chromatogram showing the peak of salicylic acid (SA) obtained with u.v. detector (similar peaks were registered in the chromatograms obtained for each of the seven experimental groups). (B) Bars represent the 2,3-DHBA:SA ratio expressed as percent of the control group. Control (C) (white bar), control group of animals injected with sodium citrate vehicle; SID (black bar), streptozotocin (STZ)-induced diabetic rats received an i.p. injection of $\mathrm{STZ}$ (60 mg/kg body weight); SID + I (gray bar), on day 15 post STZ treatment, insulin was administered s.c. to SID rats twice a day (at 0800 and $2000 \mathrm{~h}$ ) during 15 days; SID + DES (black vertically stripped bar), desferoxamine $(100 \mathrm{mg} / \mathrm{kg}$ body weight, i.p.) was administered to rats, once a day, in saline solution starting 15 days after injection of STZ and for 15 days; SID+DES + I (co-administration) (gray vertically stripped bar); SID + TEM (black horizontally stripped bar), tempol (20 mg/kg body weight, i.v.) was administered to rats, once a day, in saline solution starting 15 days after injection of STZ and for 15 days; SID + TEM+I (co-administration) (gray horizontally stripped bar). Data are expressed as means \pm s.E.M. for at least four rats for each experimental group. (C) Lipid peroxidation levels, expressed as nmol of MDA/mg of protein, were determined in liver homogenates of all experimental groups: control, SID, SID + I, SID + DES, SID + DES + I, SID + TEM, and SID + TEM+I. Data are expressed as mean \pm S.E.M. for at least six rats for each experimental group. $\left({ }^{*} P<0 \cdot 05\right.$ versus $C ;{ }^{*} P<0 \cdot 05$ versus $\left.S I D\right)$. 
A
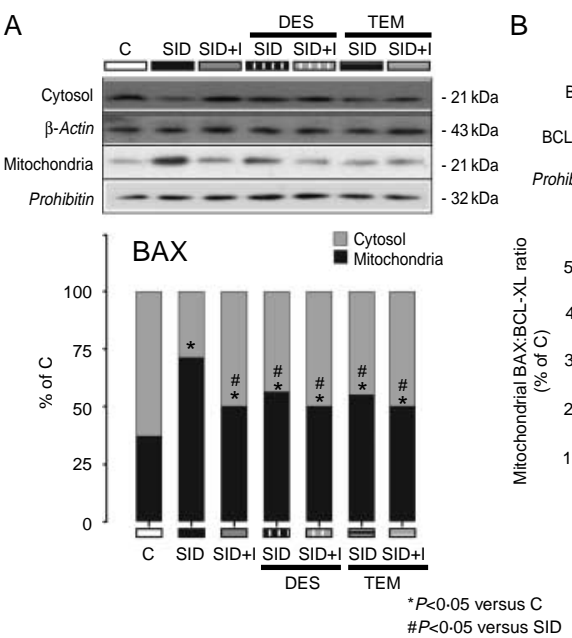

B

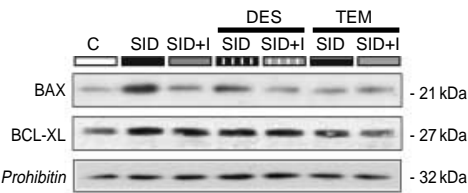

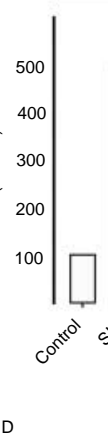

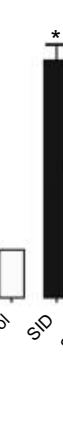

BAX:BCL-XL

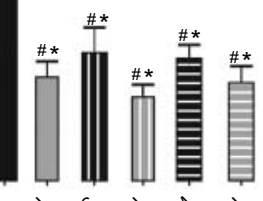

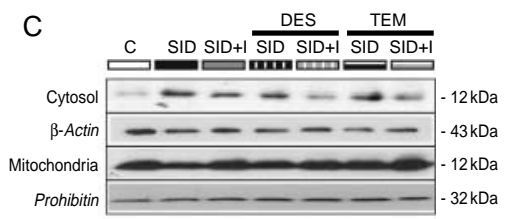

Cytochrome $c$

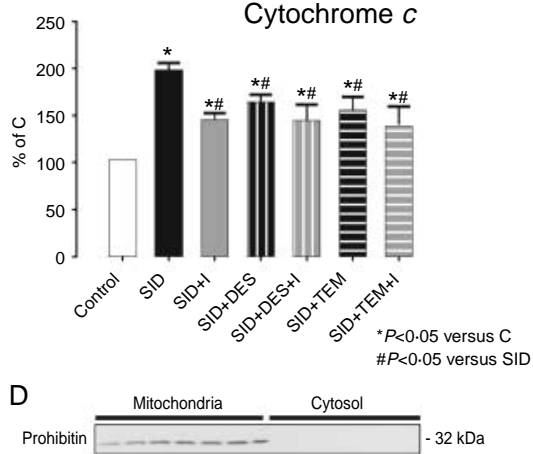

Figure 3 Immunoblot analysis of pro-apoptotic and anti-apoptotic proteins in liver subcellular fractions. The results obtained for all experimental groups are shown as follows: lane 1: control (C) (white bar), control group of animals injected with sodium citrate vehicle; lane 2: SID (black bar), streptozotocin (STZ)-induced diabetic rats received an i.p. injection of STZ (60 mg/kg body weight); lane 3: SID +I (gray bar), on day 15 post STZ treatment, insulin was administered s.c. to SID rats twice a day (at 0800 and $2000 \mathrm{~h}$ ) during 15 days; lane 4: SID + DES (black vertically stripped bar), desferoxamine $(100 \mathrm{mg} / \mathrm{kg}$ body weight, i.p.) was administered to rats, once a day, in saline solution starting 15 days after injection of STZ and for 15 days; lane 5: SID + DES + I (co-administration) (gray vertically stripped bar); lane 6: SID + TEM (black horizontally stripped bar), tempol (20 mg/kg body weight, i.v.) was administered to rats, once a day, in saline solution starting 15 days after injection of STZ and for 15 days; lane 7: SID + TEM + I (co-administration) (gray horizontally stripped bar). (A) Mitochondrial and cytosolic BAX protein expression. Typical examples of western blots are shown in top panel for each experimental group. The accompanying bars represent the densitometry expressed in percentage from six separate animal sets, considering control as $100 \%$. Data are expressed as means \pm S.E.M. (B) Mitochondrial BCL-XL protein expression. Typical examples of western blots are shown in top panel for each experimental group. The accompanying bars represent mitochondrial BAX:BCL-XL ratio expressed as percent of the control group of the densitometry obtained for BAX and BCL-XL. Data are expressed as means \pm s.E.M for at least six rats for each experimental group. (C) Mitochondrial and cytosolic cytochrome $c$ expression. Typical examples of western blots are shown in top panel for each experimental group. The accompanying bars represent the densitometry expressed in percentage from six separate animal sets, considering control as 100\%. Data are expressed as means \pm S.E.M. (D) Mitochondrial and cytosolic prohibitin expression. Typical example of western blot is shown to assess purification in differential centrifugation steps.

$(P<0 \cdot 05)$. The caspase- 3 activity was significantly decreased by insulin treatment when compared to SID rats $(P<0 \cdot 05)$, while no difference was observed when compared to the control group. By contrast, treatment with antioxidants/ hydroxyl radical scavengers resulted in a decreased casapase-3 activity although without reaching the levels of the control group $(P<0 \cdot 05)$. Co-administration of insulin and DES or TEM to SID rats produced a reduction of caspase-3 activity, reaching the control values.

Diabetic state significantly increased the AI when compared to the control group $(P<0 \cdot 05)$, while treatment with insulin significantly attenuated the increment in this parameter when compared to the SID group $(P<0 \cdot 05)$, reaching the control values (Fig. 4B). Treatment with antioxidants/hydroxyl radical scavengers resulted in a decreased AI but without reaching the levels of the control group. Co-administration of insulin and DES or TEM to SID rats produced a reduction of $\mathrm{AI}$, reaching the $C$ values $(P<0 \cdot 05$ versus SID $)$.

In Fig. 4C, a representative TUNEL assay for control, SID, and SID + I is showed. TUNEL-positive signal is maximal in the SID group and it is clear that after insulin treatment, there is a significant reduction of TUNEL-positive cells. In hepatic tissue section, the occurrence of apoptosis was confirmed by hematoxylin and eosin staining. Typical features of apoptosis, such as cellular shrinking with cytoplasmic acidophilia, condensation, and margination of the chromatin, are shown in Fig. 4D.

In no case, the careful histological analysis of liver sections stained with hematoxylin-eosin showed inflammatory foci or necrosis.

\section{Analysis of XIAP protein expression and Xiap $m R N A$ levels}

As described in the introduction and previously (Nakagami et al. 2002, Jiang \& Wang 2004), the translocation of BAX protein into mitochondrial membrane is accompanied by cytochrome $c$ release from mitochondria to cytosol, which produces a significant increase in casapase- 3 activity, leading to cell death by apoptosis. Insulin treatment produced a significant diminution, but without reaching the control values, in mitochondrial BAX protein and cytosolic cytochrome $c$. Interestingly, the activity of caspase- 3 and the AI decreased, reaching the control values. 
A Caspase-3 activity

\section{B}

Apoptotic index
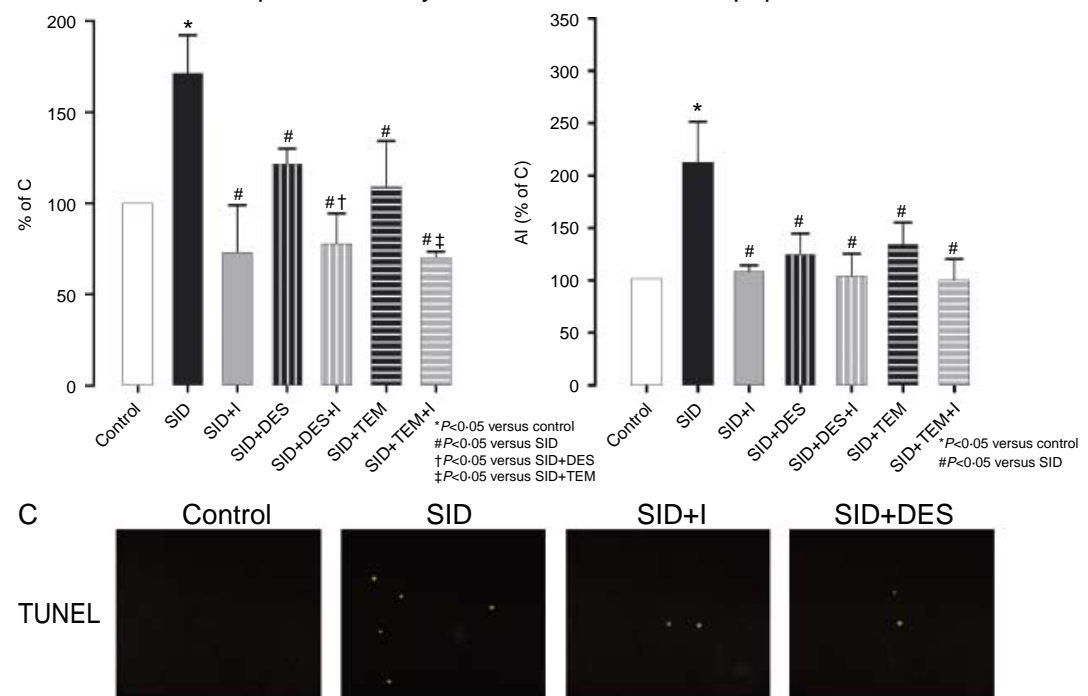

SID
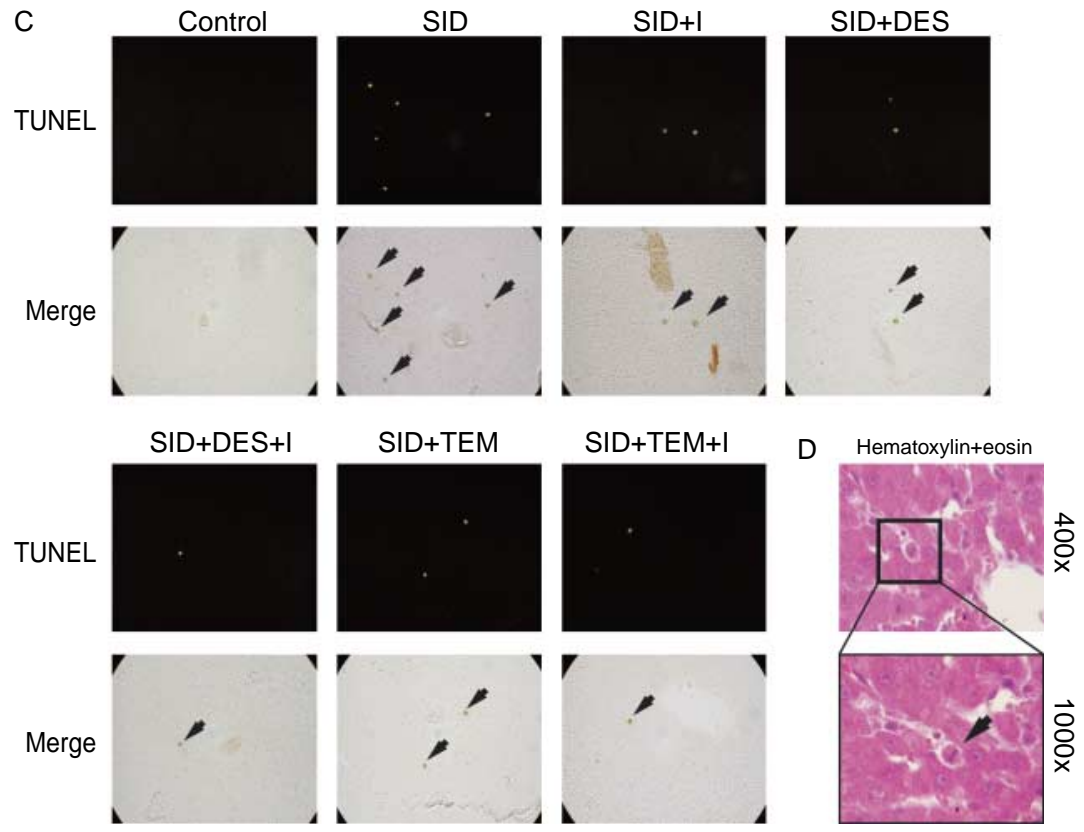



Figure 4 (A) Effect of diabetic state and insulin treatment on caspase-3 activity. The activity of caspase-3 was determined by means of a fluorometric assay. The bars represent activity expressed in percentage, considering control as $100 \%$. Data are expressed as means \pm S.E.M for at least six rats for each experimental group. Control (C) (white bar), control group of animals injected with sodium citrate vehicle; SID (black bar), streptozotocin (STZ)-induced diabetic rats received an i.p. injection of STZ (60 mg/kg body weight); SID + I (gray bar), on day 15 post STZ treatment, insulin was administered s.c. to SID rats twice a day (at 0800 and $2000 \mathrm{~h}$ ) during 15 days; SID + DES (black vertically stripped bar), desferoxamine $(100 \mathrm{mg} / \mathrm{kg}$ body weight, i.p.) was administered to rats, once a day, in saline solution starting 15 days after injection of STZ and for 15 days; SID + DES + I (co-administration) (gray vertically stripped bar); SID + TEM (black horizontally stripped bar), tempol $(20 \mathrm{mg} / \mathrm{kg}$ body weight, i.v.) was administered to rats, once a day, in saline solution starting 15 days after injection of STZ and for 15 days; SID + TEM + I (co-administration) (gray horizontally stripped bar) $\left({ }^{*} P<0.05\right.$ versus $C ;{ }^{\sharp} P<0.05$ versus SID; ${ }^{+} P<0.05$ versus SID + DES; ${ }^{\ddagger} P<0.05$ versus SID + TEM). (B) Effect of diabetic state and insulin treatment on liver apoptosis. Apoptotic index (AI) was expressed as percentage of apoptotic cells scored per 10000 hepatocytes per slide at a magnification of $400 \times$. The bands represent Al considering control as $100 \%$. Data are expressed as means \pm s.E.M. for at least six rats for each experimental group. (C) TUNEL assay. A representative TUNEL assay is showed which was performed on liver slides taken from the control, SID, SID + I, SID + DES, SID + DES + I, SID + TEM, and SID + TEM+I groups to determine the number of apoptotic cells. (D) Representative photographs of apoptotic and normal cells are shown stained with hematoxylin-eosin for the morphological analysis. Full colour version of this figure available via http://dx.doi.org/10.1677/JOE-09-0462 
Extensive data from both in vitro and in vivo systems have demonstrated that increasing XIAP, a member of the inhibitor family of apoptosis proteins (IAPs), can suppress apoptosis triggered by diverse stimuli (Case et al. 1999, Wang et al. 2007). XIAP can bind directly to procaspase-9 and activated caspase-3, preventing apoptosis (Roucou et al. 2001). To address whether the anti-apoptotic action of insulin on the liver is exerted through XIAP activation, the immunoblot analysis of cytosolic XIAP was performed. Our results show that there was a decrease in the expression of this protein in SID rats when compared to the control group (Fig. 5A, $P<0 \cdot 05$ ). Interestingly, insulin significantly increased XIAP protein. Administration of DES or TEM did not produce a significant increase of XIAP protein in cytoplasm when compared to the SID group (Fig. 5A, $P<0 \cdot 05)$. Next, we investigated whether the action of insulin is exerted through mRNA induction. Figure $5 \mathrm{~B}$ shows a marked diminution of Xiap mRNA levels in the SID group, whereas the insulin treatment revealed Xiap mRNA induction.

Taken together, these data suggest that in diabetes, hyperglycemia increases the production of ${ }^{\circ} \mathrm{OH}$ in the liver, leading to the translocation of pro-apoptotic protein Bax from cytoplasm to mitochondria, increasing the release of cytochrome $c$ from mitochondria to cytosol. This event leads

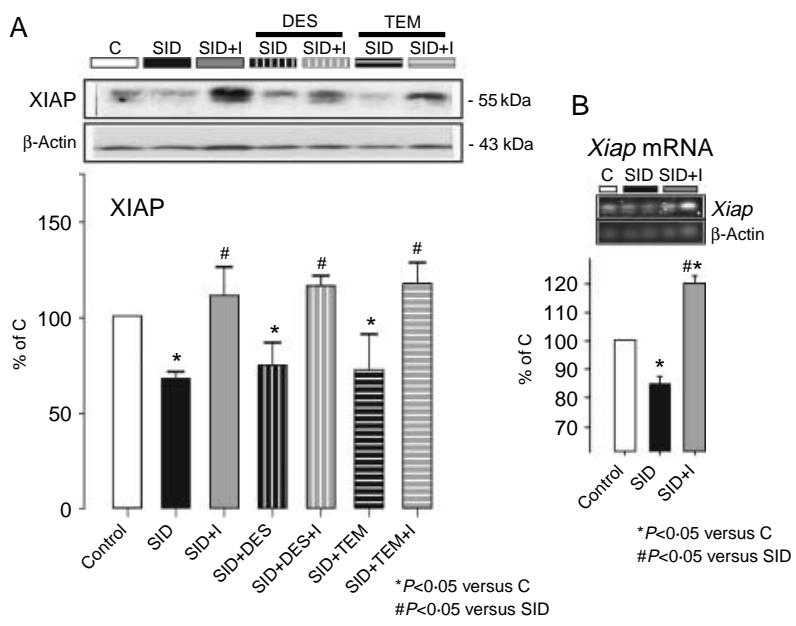

Figure 5 (A) Immunoblot analysis of XIAP expression in liver cytosolic fraction. Lane 1, control (C) (white bar); lane 2, SID (black bar); lane 3, SID + I (gray bar); lane 4, SID + DES (black vertically stripped bar); lane 5, SID + DES + I (gray vertically stripped bar); lane 6, SID + TEM (black horizontally stripped bar); lane 7, SID + TEM + I (gray horizontally stripped bar). The accompanying bars represent the densitometry expressed in percentage from six separate animal sets, considering control as $100 \%$. Data are expressed as means \pm s.E.M. (B) Insulin-induced up-regulation of Xiap hepatic mRNA. Total mRNA was isolated, and Xiap and $\beta$-actin mRNAs were assessed by RT-PCR analysis. Relative mRNA levels were quantitated, and Xiap levels were normalized to $\beta$-actin mRNA, and the ratio is expressed in arbitrary units. Ratios are presented in graphical form considering control as 100\% (mean \pm S.E.M.), and the data are representative of four experiments. to the activation of caspase-3, which coupled with the decline of anti-apoptotic protein XIAP, and conduces to apoptotic cell death. Insulin, through the reduction of hyperglycemia, helps to decrease the production of ${ }^{\circ} \mathrm{OH}$ radical, which produces a diminution in the translocation of BAX from cytosol to mitochondria and cytochrome $c$ release, although not reaching the values of the control group. Interestingly, however, there was a normalization of the activity of caspase3 and AI. These results may be explained by the induction of anti-apoptotic protein XIAP by insulin; this fact was demonstrated, to our knowledge, for the first time.

\section{Discussion}

The results obtained from this study demonstrate that apoptosis occurs in the diabetic liver. Importantly, this study has identified that ${ }^{\circ} \mathrm{OH}$ contributes partially to mitochondrial cytochrome $c$ release and caspase- 3 activation, which are associated with hyperglycemia-induced liver apoptosis. Furthermore, our results show that insulin treatment of diabetic rats produces a decrease in hepatic apoptosis, at least in part, by induction of the IAP (XIAP).

Diabetes is known to be a major disorder in which oxidative stress and free radical production have been implicated through several lines of evidence (Hinokio et al. 1999, Suzuki et al. 1999, Brownlee 2001). ROS have been defined as an autocatalytic mechanism that can lead to programed cell death (apoptosis; Jones et al. 2000). Regulation of cell death by apoptosis may be another determinant of liver structure and lesion formation (Koniaris et al. 2003). It has become increasingly clear that the process of cell death by apoptosis is a relatively ubiquitous phenomenon in a variety of cell types, including hepatic cells (Patel et al. 1999). The mechanisms regulating this process are complex and incompletely understood.

To study the role of ${ }^{\circ} \mathrm{OH}$ in LPO and in apoptosis in the liver of STZ-induced diabetes rats, diabetic animals were treated with the potent iron chelator DES (Knecht \& Mason 1993) and in another set of experiments, with a direct scavenger of hydroxyl radicals TEM, which has also been reported to reduce the formation of ${ }^{\circ} \mathrm{OH}$ by scavenging superoxide anions (Chatterjee et al. 2000). The strong inhibition elicited by both DES and TEM on LPO and apoptosis clearly establishes a connection between ${ }^{\circ} \mathrm{OH}$ production and both LPO levels and apoptosis. Our in vivo studies demonstrated that hyperglycemia leads to an increase in ${ }^{\circ} \mathrm{OH}$ production in rat liver, which was significantly reduced by both TEM and DES. Co-administration of both DES/insulin and TEM/insulin did not provide any additional beneficial effects compared to that obtained using either DES or TEM or insulin alone. However, treatment with TEM shows a larger reduction of LPO in SID rats than the one observed in the treatment with DES. It is known that TEM reduces the formation of ${ }^{\circ} \mathrm{OH}$ either by scavenging 
superoxide anions or by reducing the intracellular concentrations of $\mathrm{Fe}^{2+}$, which could suggest that other intermediate free radicals than ${ }^{\circ} \mathrm{OH}$ are also contributing to the production of LPO observed in SID rats.

In the liver, the involvement of reactive oxygen radicals has been suggested in apoptotic cell death of hepatocytes and endothelial cells (Jaeschke 2000). It is well established that members of the Bcl-2 family are critical regulators of apoptosis in a variety of cell types and appear to be cell specific (Gibbons 1995, Evan \& Littlewood 1998, Patel et al. 1999, Li et al. 2005). BAX:BCL-XL ratio determines cell survival or death after apoptotic stimuli. BAX protein has been shown to promote cell death via homodimerization, whereas heterodimerization with BCL-XL results in cell survival (Ronco et al. 2002). Our study demonstrates that there is an increased expression of BAX and BCL-XL in the diabetic state. Therefore, while the expression of BCL-XL was also augmented by insulin treatment, pro-apoptotic BAX protein showed a diminution when compared to SID but without reaching the control values. We propose that during the diabetic state there is a relative prevalence of BAX, which promotes cell death by apoptosis. Moreover, we demonstrate that all the treatments (insulin, DES, and/or TEM) produced a significant diminution of BAX:BCL-XL ratio.

It is well established that induction of BAX protein and its translocation from the cytosol to the mitochondria lead to the release of cytochrome $c$, which results in caspase- 3 activation inducing apoptotic cell death (Zimmermann et al. 2001). Our data show that the up-regulation of BAX may play a key role in the increase of caspase- 3 activity by the release of cytochrome $c$ from mitochondria, thereby leading to an increase of the $\mathrm{AI}$ in the diabetic state. Likewise, these data strongly suggest that insulin, DES, and TEM exert antiapoptotic actions in the liver through diminution of proapoptotic BAX protein (diminution of BAX:BCL-XL ratio). Also, the hormone treatment showed a significant diminution of AI reaching the control value due to a normal caspase- 3 activity. Importantly, the present study demonstrated that insulin attenuated hyperglycemia-induced liver apoptosis through decreasing ${ }^{\circ} \mathrm{OH}$ production.

A large body of evidence has shown the mediation by PI3K and AKT in the anti-apoptotic action of insulin in a variety of cell types (Lawlor \& Alessi 2001, Xi et al. 2005, Ricci et al. 2008). AKT is required to maintain the pro-apoptotic protein BAD inactive (Fernando \& Wimalasena 2004). Phosphorylated $\mathrm{BAD}$ is sequestered away from the site of action in the mitochondria by binding to cytosolic 14-3-3 proteins (Datta et al. 1997, Yano et al. 1998).

In our experimental model, we note that the treatment with insulin induces AKT activation and then BAD cytosolic sequestration and decreased levels of mitochondrial Bad (Fig. 1). Our data show that the regulatory subunit $\mathrm{p} 85 \alpha$ of PI3K exhibits a significant increase in comparison with SID (reaching the control values), which leads to the activation of AKT in agreement with other authors who suggest that the regulatory subunits can modulate the signals of insulin, i.e. an increase in $\mathrm{p} 85 \alpha$ leads to an increase in AKT activity (Ueki et al. 2003).

In this study, SID rats show mitochondrial cytochrome $c$ release, leading to increased activity of caspase-3. As an unexpected finding, insulin treatment of SID does not inhibit mitochondrial release of cytochrome $c$ fully, while the activity of caspase-3 shows a complete normalization. One possible hypothesis that could explain this dissociation between cytochrome $c$ and caspase- 3 activity may be by the action of the IAPs. IAPs are a family of proteins that have been identified as potent cellular caspase inhibitors (Roucou et al. 2001). A member of this family is XIAP, which inhibits the caspases that participate in the initiation of the apoptosis cascade (e.g. caspase-9) as well as those that participate in terminal events of the apoptosis cascade (e.g. caspase-3; Holcik \& Korneluk 2001). Extensive data from both in vitro and in vivo systems have demonstrated that increasing XIAP can suppress apoptosis triggered by diverse stimuli (Case et al. 1999, Kugler et al. 2000). Moreover, Wang et al. (2007) have described a diminution of XIAP in muscle of insulindeficient mice. We checked XIAP as an endogenous protein that would act at the terminal step of apoptosis. Our data show that XIAP is decreased in the liver of insulin-deficient

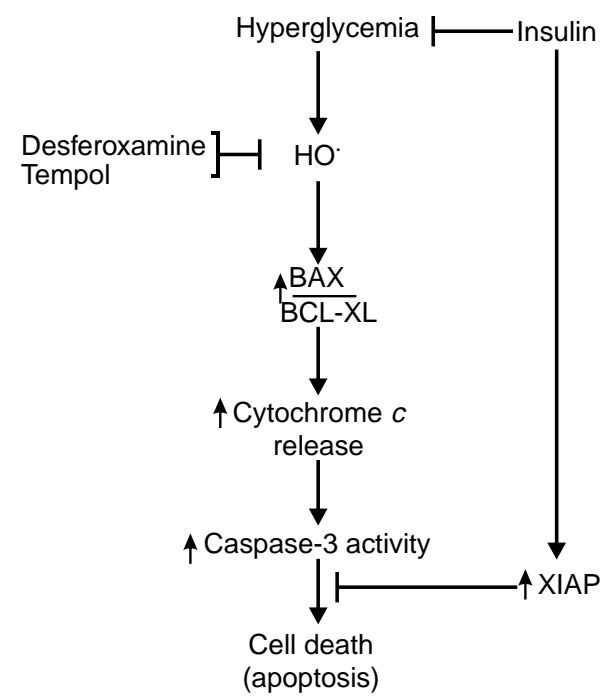

Figure 6 Proposed mechanism for diabetes enhanced apoptosis in rat liver. STZ-induced hyperglycemia increased BAX more than $\mathrm{BCL}-\mathrm{XL}$ protein, and also induced translocation from cytosol to mitochondrial membrane leading to cytochrome $c$ release and consequent activation of caspase-3 leading to apoptosis. Inhibition of ${ }^{\circ} \mathrm{OH}$ production by two known inhibitors (desferoxamine or tempol) blocks the translocation of BAX and concomitant cytochrome $c$ release. Insulin decreases hyperglycemia, thus leading to an attenuated ${ }^{\circ} \mathrm{OH}$ production, and consequently attenuates BAX protein mitochondrial levels, leading to the inhibition of caspase-3. Overall, we consider that in STZ-induced diabetes, hyperglycemia, in part via ${ }^{\circ} \mathrm{OH}$, increases apoptosis through the BAX-caspase pathway. On the other hand, insulin significantly increases XIAP, which is a potent caspase inhibitor, resulting in an inhibition of liver apoptosis. 
rat (SID group, Fig. 5). Also, we found that the treatment with insulin increases the XIAP expression levels by inducing its mRNA (Fig. 5).

This is the first study to show that insulin has anti-apoptotic action, at least in part, through XIAP induction in rat liver. Other authors had reported that XIAP is stabilized via the activation of AKT in Kupffer cells (Ashare et al. 2007). Moreover, XIAP is known to be phosphorylated at serine 87 by Akt, and this phosphorylation stabilizes the protein (Dan et al. 2004). In this sense, our results show increased phosphorylation of AKT in insulin-treated groups, contributing probably to XIAP stabilization.

Taken together, our findings demonstrate that insulin treatment impairs the increase of ${ }^{\circ} \mathrm{OH}$ production generated by the diabetic state in the rat liver. High levels of this reactive species play an important role in the increase of hepatic LPO observed in the diabetic state, and finally lead to increased pro-apoptotic events by altering the fine balance between the expression of pro-apoptotic and anti-apoptotic proteins. The relative concentration of these proteins is an essential determinant of their final impact on cell fate, and promotion of pro-apoptotic events plays a central role in the development of liver complications in diabetes. Importantly, this study demonstrates that insulin reduced ${ }^{\circ} \mathrm{OH}$ levels caused by hyperglycemia and exhibited an attenuation of the translocation of BAX to the mitochondria, partially affecting the release of mitochondrial cytochrome $c$ to cytoplasm and preventing the activation of caspase- 3 producing a slight anti-apoptotic effect.Interestingly, we also show that another way in which insulin exerts its anti-apoptotic action is due to its ability to increase the expression of XIAP protein that appears to be independent of the generation of ${ }^{\circ} \mathrm{OH}$.

Only the insulin treatment, but not the antioxidants/ hydroxyl radical scavenger ones, results in the reversal of the alterations observed in the diabetic state as reduced PI3K, increased mitochondrial BAD, and decreased XIAP. On the other hand, all treatments lead to a reversal of the alterations observed in the diabetic state as increased ${ }^{\circ} \mathrm{OH}$ production, LPO levels, increased BAX:BCL-XL ratio, increased cytochrome $c$ release from the mitochondria, augmentation of cytochrome $c$, and increase of AI.

Overall, we demonstrated that hyperglycemia enhances $\cdot \mathrm{OH}$ levels, induction of BAX protein, and translocation of BAX from cytosol to the mitochondria, leading to the release of cytochrome $c$ and consequent activation of caspase- 3 with resultant apoptosis. Insulin leads to a decrease of ${ }^{\circ} \mathrm{OH}$ levels, which produces a slight reduction of BAX:BCL-XL ratio, leading to a mild diminution of cytochrome $c$ release from mitochondria to cytosol, and a significant decrease in both caspase-3 activity and AI. Only insulin increases IAP expression (XIAP; Fig. 6).

Taken together, our study demonstrates a partial contribution of $\mathrm{OH}$ in hyperglycemia-induced liver apoptosis, which may contribute to the disease process in diabetic liver. Also, a new anti-apoptotic signal for insulin is shown, given by an increase in XIAP expression. The control of hepatic ${ }^{\circ} \mathrm{OH}$ production and XIAP levels in the diabetic state could be of therapeutic relevance for improvement or delay of the hepatic complications linked to chronic hyperglycemia.

\section{Declaration of interest}

The authors declare that there is no conflict of interest that could be perceived as prejudicing the impartiality of the research reported.

\section{Funding}

This work was supported by research grants from ANPCyT (PICT no. 32413, CEC) and from CONICET (PIP no. 5531, CEC).

\section{Acknowledgements}

We especially wish to thank Marcelo Luquita for his technical assistance in performing the HPLC assays. We also thank Bioq. Cecilia Basiglio for English revision.

\section{References}

Ashare A, Monick MM, Nymon AB, Morrison JM, Noble M, Powers LS, Yarovinsky TO, Yahr TL \& Hunninghake GW 2007 Pseudomonas aeruginosa delays Kupffer cell death via stabilization of the X-chromosomelinked inhibitor of apoptosis protein. Journal of Immunology 179 505-513.

Barneo L, Esteban MM, Garcia-Pravia C, Diaz F \& Marin B 1990

Normalization of the altered liver function tests after islet transplantation in diabetic rats. Diabetes \& Metabolism 16 284-289.

Bell DS \& Allbright E 2007 The multifaceted associations of hepatobiliary disease and diabetes. Endocrine Practice 13 300-312.

Brownlee M 2001 Biochemistry and molecular cell biology of diabetic complications. Nature 414 813-820.

Carnovale CE \& Rodriguez Garay EA 1984 Reversible impairment of hepatobiliary function induced by streptozotocin in the rat. Experientia 40 248-250.

Carnovale CE, Marinelli RA \& Rodriguez Garay EA 1986 Bile flow decrease and altered bile composition in streptozotocin-treated rats. Biochemical Pharmacology 35 2625-2628.

Case SS, Price MA, Jordan CT, Yu XJ, Wang L, Bauer G, Haas DL, Xu D, Stripecke R, Naldini L et al. 1999 Stable transduction of quiescent CD34(+)CD38(-) human hematopoietic cells by HIV-1-based lentiviral vectors. PNAS $962988-2993$.

Chatila R \& West AB 1996 Hepatomegaly and abnormal liver tests due to glycogenosis in adults with diabetes. Medicine 75 327-333.

Chatterjee PK, Cuzzocrea S, Brown PA, Zacharowski K, Stewart KN, Mota-Filipe H \& Thiemermann C 2000 Tempol, a membrane-permeable radical scavenger, reduces oxidant stress-mediated renal dysfunction and injury in the rat. Kidney International 58 658-673.

Dan HC, Sun M, Kaneko S, Feldman RI, Nicosia SV, Wang HG, Tsang BK \& Cheng JQ 2004 Akt phosphorylation and stabilization of X-linked inhibitor of apoptosis protein (XIAP). Journal of Biological Chemistry 279 5405-5412.

Datta SR, Dudek H, Tao X, Masters S, Fu H, Gotoh Y \& Greenberg ME 1997 Akt phosphorylation of BAD couples survival signals to the cell-intrinsic death machinery. Cell 91 231-241.

Evan G \& Littlewood T 1998 A matter of life and cell death. Science 281 1317-1322.

Fernandes AA, Novelli EL, Okoshi K, Okoshi MP, Muzio BP, Guimaraes JF \& Junior AF 2009 Influence of rutin treatment on biochemical alterations in experimental diabetes. Biomedicine and Pharmacotherapy 64 214-219. 
Fernando RI \& Wimalasena J 2004 Estradiol abrogates apoptosis in breast cancer cells through inactivation of BAD: Ras-dependent nongenomic pathways requiring signaling through ERK and Akt. Molecular Biology of the Cell 15 3266-3284.

Fraser A \& Evan G 1996 A license to kill. Cell 85 781-784.

Galetic I, Andjelkovic M, Meier R, Brodbeck D, Park J \& Hemmings BA 1999 Mechanism of protein kinase B activation by insulin/insulin-like growth factor-1 revealed by specific inhibitors of phosphoinositide 3-kinase - significance for diabetes and cancer. Pharmacology \& Therapeutics $\mathbf{8 2}$ $409-425$.

Gibbons GH 1995 Mechanisms of vascular remodeling in hypertension: role of autocrine-paracrine vasoactive factors. Current Opinion in Nephrology and Hypertension 4 189-196.

Gold R, Schmied M, Giegerich G, Breitschopf H, Hartung HP, Toyka KV \& Lassmann H 1994 Differentiation between cellular apoptosis and necrosis by the combined use of in situ tailing and nick translation techniques. Laboratory Investigation 71 219-225.

Green DR \& Reed JC 1998 Mitochondria and apoptosis. Science 281 1309-1312.

Grootveld M \& Halliwell B 1986 Aromatic hydroxylation as a potential measure of hydroxyl-radical formation in vivo. Identification of hydroxylated derivatives of salicylate in human body fluids. Biochemical Journal 237 499-504.

Ha H, Kim C, Son Y, Chung MH \& Kim KH 1994 DNA damage in the kidneys of diabetic rats exhibiting microalbuminuria. Free Radical Biology and Medicine 16 271-274.

Harrison SA, Brunt EM, Goodman ZD \& Di Bisceglie AM 2006 Diabetic hepatosclerosis: diabetic microangiopathy of the liver. Archives of Pathology and Laboratory Medicine 130 27-32.

Hinokio Y, Suzuki S, Hirai M, Chiba M, Hirai A \& Toyota T 1999 Oxidative DNA damage in diabetes mellitus: its association with diabetic complications. Diabetologia 42 995-998.

Holcik M \& Korneluk RG 2001 XIAP, the guardian angel. Nature Reviews. Molecular Cell Biology 2 550-556.

Hwang HJ, Kim SW, Lim JM, Joo JH, Kim HO, Kim HM \& Yun JW 2005 Hypoglycemic effect of crude exopolysaccharides produced by a medicinal mushroom Phellinus baumii in streptozotocin-induced diabetic rats. Life Sciences 76 3069-3080.

Jaeschke H 2000 Reactive oxygen and mechanisms of inflammatory liver injury. Journal of Gastroenterology and Hepatology 15 718-724.

Jiang X \& Wang X 2004 Cytochrome C-mediated apoptosis. Annual Review of Biochemistry 73 87-106.

Jones BE, Lo CR, Liu H, Pradhan Z, Garcia L, Srinivasan A, Valentino KL \& Czaja MJ 2000 Role of caspases and NF-kappaB signaling in hydrogen peroxide- and superoxide-induced hepatocyte apoptosis. American Journal of Physiology. Gastrointestinal and Liver Physiology 278 G693-G699.

Karunanayake EH, Hearse DJ \& Mellows G 1974 The synthesis of $\left[{ }^{14} \mathrm{C}\right]$ streptozotocin and its distribution and excretion in the rat. Biochemical Journal 142 673-683.

Katso R, Okkenhaug K, Ahmadi K, White S, Timms J \& Waterfield MD 2001 Cellular function of phosphoinositide 3-kinases: implications for development, homeostasis, and cancer. Annual Review of Cell and Development Biology 17 615-675.

Kaur H \& Halliwell B 1994 Detection of hydroxyl radicals by aromatic hydroxylation. Methods in Enzymology 233 67-82.

Kiritoshi S, Nishikawa T, Sonoda K, Kukidome D, Senokuchi T, Matsuo T, Matsumura T, Tokunaga H, Brownlee M \& Araki E 2003 Reactive oxygen species from mitochondria induce cyclooxygenase-2 gene expression in human mesangial cells: potential role in diabetic nephropathy. Diabetes $\mathbf{5 2}$ 2570-2577.

Klainguti M, Aigner S, Kilo J, Eppenberger HM, Mandinova A, Aebi U, Schaub MC, Shaw SG, Luscher TF \& Atar D 2000 Lack of nuclear apoptosis in cardiomyocytes and increased endothelin-1 levels in a rat heart model of myocardial stunning. Basic Research in Cardiology 95 308-315.

Knecht KT \& Mason RP 1993 In vivo spin trapping of xenobiotic free radical metabolites. Archives of Biochemistry and Biophysics 303 185-194.

Koniaris LG, McKillop IH, Schwartz SI \& Zimmers TA 2003 Liver regeneration. Journal of the American College of Surgeons 197 634-659.
Kugler S, Straten G, Kreppel F, Isenmann S, Liston P \& Bahr M 2000 The $\mathrm{X}$-linked inhibitor of apoptosis (XIAP) prevents cell death in axotomized CNS neurons in vivo. Cell Death and Differentiation 7 815-824.

Laaksonen DE, Atalay M, Niskanen L, Uusitupa M, Hanninen O \& Sen CK 1996 Increased resting and exercise-induced oxidative stress in young IDDM men. Diabetes Care 19 569-574.

Lawlor MA \& Alessi DR 2001 PKB/Akt: a key mediator of cell proliferation, survival and insulin responses? Journal of Cell Science 114 2903-2910.

Li H, Telemaque S, Miller RE \& Marsh JD 2005 High glucose inhibits apoptosis induced by serum deprivation in vascular smooth muscle cells via upregulation of Bcl-2 and Bcl-xl. Diabetes 54 540-545.

Liu X, Kim CN, Yang J, Jemmerson R \& Wang X 1996 Induction of apoptotic program in cell-free extracts: requirement for dATP and cytochrome c. Cell 86 147-157.

Lowry OH, Rosebrough NJ, Farr AL \& Randall RJ 1951 Protein measurement with the Folin phenol reagent. Journal of Biological Chemistry 193 265-275.

Marangiello R \& Giorgetti R 1996 A case of glycogenosis in a patient with insulin dependent diabetes. Minerva Pediatrica 48 279-281.

McLennan SV, Heffernan S, Wright L, Rae C, Fisher E, Yue DK \& Turtle JR 1991 Changes in hepatic glutathione metabolism in diabetes. Diabetes $\mathbf{4 0}$ 344-348.

Moreira PI, Rolo AP, Sena C, Seica R, Oliveira CR \& Santos MS 2006 Insulin attenuates diabetes-related mitochondrial alterations: a comparative study. Medicinal Chemistry 2 299-308.

Nakagami H, Morishita R, Yamamoto K, Taniyama Y, Aoki M, Yamasaki K, Matsumoto K, Nakamura T, Kaneda Y \& Ogihara T 2002 Hepatocyte growth factor prevents endothelial cell death through inhibition of bax translocation from cytosol to mitochondrial membrane. Diabetes $\mathbf{5 1}$ 2604-2611.

Nawano M, Ueta K, Oku A, Arakawa K, Saito A, Funaki M, Anai M, Kikuchi M, Oka Y \& Asano T 1999 Hyperglycemia impairs the insulin signaling step between PI3-kinase and Akt/PKB activations in ZDF rat liver. Biochemical and Biophysical Research Communications 266 252-256.

Nishikawa T, Edelstein D, Du XL, Yamagishi S, Matsumura T, Kaneda Y, Yorek MA, Beebe D, Oates PJ, Hammes HP et al. 2000 Normalizing mitochondrial superoxide production blocks three pathways of hyperglycaemic damage. Nature 404 787-790.

Ohkawa H, Ohishi N \& Yagi K 1979 Assay for lipid peroxides in animal tissues by thiobarbituric acid reaction. Analytical Biochemistry 95 351-358.

Ohkuwa T, Sato Y \& Naoi M 1995 Hydroxyl radical formation in diabetic rats induced by streptozotocin. Life Sciences 56 1789-1798.

Park KS, Kim JH, Kim MS, Kim JM, Kim SK, Choi JY, Chung MH, Han B, Kim SY \& Lee HK 2001 Effects of insulin and antioxidant on plasma 8-hydroxyguanine and tissue 8-hydroxydeoxyguanosine in streptozotocin-induced diabetic rats. Diabetes 50 2837-2841.

Patel T, Steer CJ \& Gores GJ 1999 Apoptosis and the liver: a mechanism of disease, growth regulation, and carcinogenesis. Hepatology 30 811-815.

Porte D Jr \& Schwartz MW 1996 Diabetes complications: why is glucose potentially toxic? Science 272 699-700.

Pryor WA \& Godber SS 1991 Noninvasive measures of oxidative stress status in humans. Free Radical Biology and Medicine 10 177-184.

Ricci C, Jong CJ \& Schaffer SW 2008 Proapoptotic and antiapoptotic effects of hyperglycemia: role of insulin signaling. Canadian Journal of Physiology and Pharmacology 86 166-172.

Ronco MT, deAlvarez ML, Monti J, Carrillo MC, Pisani G, Lugano MC \& Carnovale CE 2002 Modulation of balance between apoptosis and proliferation by lipid peroxidation (LPO) during rat liver regeneration. Molecular Medicine 8 808-817.

Ronco MT, Alvarez ML, Monti JA, Carrillo MC, Pisani GB, Lugano MC \& Carnovale CE 2004 Role of nitric oxide increase on induced programmed cell death during early stages of rat liver regeneration. Biochimica et Biophysica Acta 1690 70-76.

Ronco MT, Frances DE, Ingaramo PI, Quiroga AD, Alvarez ML, Pisani GB, Revelli SS \& Carnovale CE 2009 Tumor necrosis factor alpha induced by Trypanosoma cruzi infection mediates inflammation and cell death in the liver of infected mice. Cytokine 49 64-72.

Roucou X, Antonsson B \& Martinou JC 2001 Involvement of mitochondria in apoptosis. Cardiology Clinics 19 45-55. 
Saxena AK, Srivastava P, Kale RK \& Baquer NZ 1993 Impaired antioxidant status in diabetic rat liver. Effect of vanadate. Biochemical Pharmacology $\mathbf{4 5}$ 539-542.

Shepherd PR, Withers DJ \& Siddle K 1998 Phosphoinositide 3-kinase: the key switch mechanism in insulin signalling. Biochemical Journal 333 471-490.

Suzuki S, Hinokio Y, Komatu K, Ohtomo M, Onoda M, Hirai S, Hirai M, Hirai A, Chiba M, Kasuga S et al. 1999 Oxidative damage to mitochondrial DNA and its relationship to diabetic complications. Diabetes Research and Clinical Practice 45 161-168.

Tsai LY, Lee KT \& Liu TZ 1998 Evidence for accelerated generation of hydroxyl radicals in experimental obstructive jaundice of rats. Free Radical Biology and Medicine 24 732-737.

Tzung SP, Fausto N \& Hockenbery DM 1997 Expression of Bcl-2 family during liver regeneration and identification of $\mathrm{Bcl}-\mathrm{x}$ as a delayed early response gene. American Journal of Pathology 150 1985-1995.

Ueki K, Fruman DA, Yballe CM, Fasshauer M, Klein J, Asano T, Cantley LC \& Kahn CR 2003 Positive and negative roles of p85 alpha and p85 beta regulatory subunits of phosphoinositide 3-kinase in insulin signaling. Journal of Biological Chemistry 278 48453-48466.

Virkamaki A, Ueki K \& Kahn CR 1999 Protein-protein interaction in insulin signaling and the molecular mechanisms of insulin resistance. Journal of Clinical Investigation 103 931-943.

Wang XH, Hu J, Du J \& Klein JD 2007 X-chromosome linked inhibitor of apoptosis protein inhibits muscle proteolysis in insulin-deficient mice. Gene Therapy 14 711-720.

Wen JJ, Yachelini PC, Sembaj A, Manzur RE \& Garg NJ 2006 Increased oxidative stress is correlated with mitochondrial dysfunction in chagasic patients. Free Radical Biology and Medicine 41 270-276.

West IC 2000 Radicals and oxidative stress in diabetes. Diabetic Medicine 17 171-180.
Winiarska K, Drozak J, Wegrzynowicz M, Fraczyk T \& Bryla J 2004 Diabetes-induced changes in glucose synthesis, intracellular glutathione status and hydroxyl free radical generation in rabbit kidney-cortex tubules. Molecular and Cellular Biochemistry 261 91-98.

Xi X, Gao L, Hatala DA, Smith DG, Codispoti MC, Gong B, Kern TS \& Zhang JZ 2005 Chronically elevated glucose-induced apoptosis is mediated by inactivation of Akt in cultured Muller cells. Biochemical and Biophysical Research Communications 326 548-553.

Yamamoto H, Watanabe T, Mizuno H, Endo K, Hosokawa T, Kazusaka A, Gooneratne R \& Fujita S 2001 In vivo evidence for accelerated generation of hydroxyl radicals in liver of Long-Evans Cinnamon (LEC) rats with acute hepatitis. Free Radical Biology and Medicine 30 547-554.

Yang J, Liu X, Bhalla K, Kim CN, Ibrado AM, Cai J, Peng TI, Jones DP \& Wang X 1997 Prevention of apoptosis by Bcl-2: release of cytochrome $c$ from mitochondria blocked. Science 275 1129-1132.

Yano S, Tokumitsu H \& Soderling TR 1998 Calcium promotes cell survival through CaM-K kinase activation of the protein-kinase-B pathway. Nature 396 584-587.

Young IS \& Trimble ER 1991 Measurement of malondialdehyde in plasma by high performance liquid chromatography with fluorimetric detection. Annals of Clinical Biochemistry 28 504-508.

Zimmermann KC, Bonzon C \& Green DR 2001 The machinery of programmed cell death. Pharmacology and Therapeutics 92 57-70.

\section{Received in final form 11 February 2010 \\ Accepted 17 February 2010 \\ Made available online as an Accepted Preprint 17 February 2010}

